\title{
Faktor Risiko Terjadinya Osteoporosis Pada Wanita Menopause
}

\author{
Renidayati ${ }^{\mathrm{a}}$, Clara $^{\mathrm{a}}$, Sunardi $^{\mathrm{a}}$ \\ Politeknik Kesehatan Kemenkes RI
}

\begin{abstract}
Abstrak : Two out of five Indonesian women have an increased risk of osteoporosis and found in $85 \%$ of women who have undergone menopause for over 10 years. Several risk factors for This study aims to determine risk factors for osteoporosis in postmenopausal women in Kelurahan Langgini Work Area Bangkinang Health Center Kampar Regency Year 2010 The study design is descriptive analytical approach cross-sectional. The sample in this study 51 postmenopausal women. Data processing is done using univariate and bivariate data analysis. The results obtained $33.3 \%$ of respondents had osteoporosis, $33.3 \%$ of respondents have a skinny body type, 51.0\% had an activity (sports) that are less, and $54.9 \%$ had a poor diet. So there is a significant relationship between body type, activity (exercise) and diet with the incidence of osteoporosis $P$ value $0.000<$ alpha (0.05). The study recommended to the Chief Bangkinang Health Center of Kampar Regency, a policy to conduct outreach to menopausal women as a routine program in health centers and for nurses and midwives in order to give education the importance of activities (sports) and an increase in dietary for menopausal women.
\end{abstract}

Keywords: Osteoporosis, Menopause, Body Type, activity (exercise), Diet

\begin{abstract}
Abstrak : Setiap dua hari dari 5 wanita di Indonesia memiliki resiko yang lebih besar mengalami osteoporosis. Dan ini ditemukan pada $85 \%$ wanita yang sudah mengalami menopause selama 10 tahun. Beberapa factor resiko osteoporosis adalah jenis kelamin, ukuran tubuh, diet, aktifitas / latihan, merokok dan peminum alcohol. Tujuan Penelitian ini adalah untuk mengetahui faktor resiko osteoporosis pada wanita menopause di kelurahan langgini wilayah Kerja Puskesmas Bangkinang Kabupaten Kampar tahun 2010. Desain penelitian adalah deskriptif analitik dengan pendekatan potong lintang, sampel penelitian adalah 51 wanita menopause. Pengolahan data dilakukan dengan analisa univariate dan bivariate. Hasil penelitian menunjukan 33,3\% responden mengalami osteoporosis, 33,3\% responden memiliki badan kurus, 51\% responden memiliki aktifitas rendah dari 54.9\% responden memiliki diet yang buruk. Terdapat hubungan yang bermakna antara ukuran tubuh, aktifitas (latihan) dan diet dengan kejadian osteoporosis $(\mathrm{p}=0.000)$. disarankan kepeda pimpinan Puskesmas Bangkinang untuk mengeluarkan kebijakan rutin untuk wanita menopause dan unutk perawat dan bidan agak dapat memberikan pendidikan tentang pentingnya aktifitas (latihan) den meningkatkan diet bagi wanita menopause.
\end{abstract}

Kata Kunci : Osteoporosis, Menopouse, Tipe tubuh, Latihan,Diet

Seiring kemajuan dibidang kesehatan dan kesadaran masyarakat untuk hidup sehat, berakibat semakin tinggi angka harapan hidup masyarakat Indonesia (Partono, 2009). Berdasarkan data statistik Indonesia tahun 2008, angka harapan hidup penduduk Indonesia naik dari 67,8 tahun pada periode 2000-2005 menjadi 73,6 tahun pada periode 2020-2025. Meningkatnya angka harapan hidup masyarakat di Indonesia, semakin banyak kasus-kasus yang terjadi pada manusia usia lanjut (Medicastore, 2008). 
Usia lanjut identik dengan perubahan terutama bagi wanita. Salah satu perubahan tersebut terjadi pada masa menopause. Mengalami menopause adalah suatu proses yang harus dilewati, keadaaan ini merupakan proses penuaan yang sangat alamiah dan normal pada setiap wanita. (Proverawati, 2010).

Menopause menghadirkan berbagai macam tanda dan gejala tersendiri. Tanda dan gejala dapat dilihat dari segi psikologis atau fisiknya. Gejala psikologis yang ditemukan pada wanita menopause yaitu ingatan menurun, depresi, mudah lelah, mudah marah dan gelisah. Gejala fisik yang menyertai menopause, meliputi hot flushes (semburan panas dari dada hingga wajah), night sweat (berkeringat di malam hari), dryness vaginal (kekeringan vagina), insomnia, inkontinensia urin, lebih gemuk, dan osteoporosis (Smart, 2010).

Berkurangnya hormon estrogen mengakibatkan kaum perempuan memiliki resiko lebih tinggi terkena osteoporosis terutama pada masa menopause karena hormon estrogen menurun mengakibatkan kecepatan penurunan masa tulang (Gomez, 2006).

Penyakit kerapuhan tulang melanda seluruh dunia dan telah melumpuhkan jutaan orang. WHO tahun 2007 menyatakan penyakit osteoporosis sudah saatnya mendapat perhatian yang lebih serius. Sebagian besar masyarakat masih percaya bahwa penyakit tersebut merupakan sesuatu yang tidak perlu dikhawatirkan karena dianggap suatu keadaan yang biasa terjadi pada usia lanjut (Wirakusumah, 2007).

Berdasarkan data Puslitbang Gizi Depkes tahun 2006, 2 dari 5 orang wanita Indonesia memiliki risiko osteoporosis dan pada usia lebih dari 55 tahun akan mengalami peningkatan 2 kali lebih besar dibandingkan pria. Osteoporosis pada wanita di atas 50 tahun mencapai $32,3 \%$ sementara pada pria di atas 50 tahun mencapai 28,8\% (Depkes RI, 2008).

Osteoporosis dapat menyerang semua orang, meskipun tingkat risikonya berbeda-beda. Adapun faktor risiko terjadinya osteoporosis dapat digolongkan menjadi dua kelompok yaitu faktor risiko yang tidak dapat dikendalikan seperti jenis kelamin, umur, ras, riwayat keluarga, tipe tubuh dan menopause. Sedangkan faktor risiko yang dapat dikendalikan yaitu aktivitas fisik (olahraga), diet, kebiasaan merokok dan minum minuman beralkohol (Wirakusumah, 2007).

Berdasarkan laporan Puskesmas Bangkinang tahun 2010 bahwa osteoporosis menempati urutan kedua banyaknya pasien yang datang berobat ke Puskesmas Bangkinang dengan jumlah 350 orang setelah penyakit hipertensi yang berjumlah 367 orang. Hasil wawancara dengan pemegang program mengatakan bahwa yang banyak datang berobat ke puskesmas bangkinang adalah wanita menopause usia 45 tahun keatas.

Survey awal terhadap 10 orang wanita menopause yang berumur 45-50 tahun, $40 \%$ diantaranya mengatakan bahwa mereka tidak tahu dan tidak terpikirkan akan penyakit keropos tulang. $20 \%$ mengatakan jarang minum susu karena tidak sanggup untuk membelinya dan tidak pernah mengkonsumsi suplemen ataupun vitamin. $20 \%$ tidak melakukan olahraga karena kesibukan dalam mengurus anak-anak dan cucu serta pekerjaan rumah. Berdasarkan uraian diatas peneliti melakukan penelitian tentang faktor risiko terjadinya osteoporosis pada wanita menopause di Kelurahan Langgini Wilayah Kerja Puskesmas Bangkinang Kabupaten Kampar.Penelitian ini bertujuan untuk mengetahui faktor risiko terjadinya osteoporosis pada wanita menopause di Kelurahan Langgini Wilayah Kerja Puskesmas Bangkinang Kabupaten Kampar.

\section{METODE}

Penelitian ini merupakan penelitian deskriptif analitik dengan desain penelitian cross sectional study. Penelitian ini dilaksanakan di Kelurahan Langgini wilayah kerja Puskesmas Bangkinang Kabupaten Kampar. Waktu penelitian dari 
bulan Juni sampai Desember 2010. Populasi penelitian ini adalah semua wanita menopause di Kelurahan Langgini. Sampel yang akan diambil adalah sebanyak 51 orang wanita menopause. Pengambilan sampel dilakukan dengan cara purposive sampling. Data diperoleh atau yang dikumpulkan langsung pada sumbernya. Teknik pengumpulan data dilakukan dengan wawancara dan observasi. Tahapan pengolahan data terdiri dari: Editing, coding, Entry dan Cleaning. Analisis data terdiri dari : Analisis univariat menggunakan statistik deskriptif untuk mengetahui distribusi frekuensi dari masingmasing variabel yang diteliti dan analisis bivariat yang digunakan uji statistik $C h i$ Square..

\section{HASIL DAN PEMBAHASAN}

Berdasarkan hasil penelitian yang telah dilakukan didapatkan bahwa kurang dari separoh $(33,3 \%)$ wanita menopause mengalami osteoporosis yaitu 17 orang.

Hasil penelitian sama dengan hasil penelitian yang dilakukan oleh Karolina, 2009 didapatkan bahwa sebagian besar lansia $(58,3 \%)$ memiliki tindakan pencegahan osteoporosis yang kurang. Dengan tindakan yang kurang ini secara tidak langsung akan meningkatkan kejadian osteoporosis. Penelitian ini juga didukung Javier (2010) bahwa osteoporosis terjadi akibat ketidakseimbangan antara proses demineralisasi yang lebih tinggi dan proses mineralisasi tulang. Tulang keropos ini terutama banyak dialami wanita usia menopause.

Berkurangnya hormon estrogen mengakibatkan kaum perempuan memiliki resiko lebih tinggi terkena osteoporosis terutama pada masa menopause karena hormon estrogen menurun mengakibatkan kecepatan penurunan masa tulang meningkat hal ini terjadi karena estrogen membantu penyerapan kalsium ke dalam tulang sehingga ketika kadar estrogen menurun, maka wanita akan mengalami kehilangan kalsium dari tulang dengan cepat.
Tabel 1.Distribusi Frekuensi Kejadian Osteoporosis Kelurahan Langgini

\begin{tabular}{lcc}
\hline Osteoporosis & Frekuensi & Persentase \\
\hline Tidak & 34 & 66,7 \\
Ya & 17 & 33,3 \\
Jumlah & 51 & 100 \\
\hline
\end{tabular}

Berdasarkan Tabel 2. proporsi kejadian osteoporosis, presentasenya lebih besar pada responden yang kurus $(88,2 \%)$ dibandingkan dengan responden yang gemuk $(5.9 \%)$. Hasil uji statistik chi-square didapatkan nilai $\mathrm{P}$ value sebesar $0,000<$ nilai alpha $(0,05)$, ada hubungan yang signifikan antara tipe tubuh wanita menopause dengan kejadian osteoporosis. Hasil penelitian didapatkan ada hubungan yang signifikan antara tipe tubuh wanita menopause dengan kejadian osteoporosis di Kelurahan Langgini Wilayah Kerja Puskesmas Bangkinang Kabupaten Kampar.

Beberapa wanita menopause memiliki indeks massa tubuh dibawah normal. Sehingga bentuk tubuh dari wanita menopause dikategorikan kurus. Badan yang kurus tidak dapat memberikan beban berat setiap hari pada tulang untuk mendorong pembentukan tulang, sama dengan olahraga. Badan yang kurus juga tidak dapat mempermudah produksi hormon estrogen dari jaringan lemak. Berat badan adalah faktor yang menentukan kepadatan tulang, tetapi bisa juga berfungsi memberikan perlindungan mekanis (Cosman, 2009).

Kebanyakan wanita menopause yang memiliki tubuh gemuk secara psikologis disebabkan oleh pikiran akan beban hidup yang sudah mulai berkurang untuk memikirkan anak-anak, karier dan rumah tangga. Selain itu karena perubahan hormon, pola makan yang berubah dan aktivitas yang sudah mulai menurun. 
Penelitian Sinnathamby (2010), ada hubungan postur tubuh dengan kejadian osteoporosis, didapatkan kebanyakan wanita berpostur kurus lebih rentan terkena osteoporosis.

Semakin kecil rangka tubuh maka semakin besar risiko terkena osteoporosis. Wanita yang mempunyai tubuh kurus mempunyai risiko yang lebih tinggi terkena osteoporosis dari pada yang mempunyai berat badan lebih besar. Apabila nilai massa tulang rendah maka kehilangan massa tulang yang diikuti dengan kerapuhan tulang sangat mungkin terjadi. Jika nilai puncak massa tulang tinggi maka seseorang relatif lebih kecil risikonya terkena osteoporosis.

Tabel 2. Distribusi Tipe Tubuh, olah raga, dan diet Dengan Kejadian Osteoporosi Kelurahan Langgini Tahun 2011

\begin{tabular}{|c|c|c|c|c|c|c|c|}
\hline & \multicolumn{4}{|c|}{ Osteoporosis } & \multicolumn{2}{|c|}{ Total } & \multirow[t]{3}{*}{ Nilai $P$} \\
\hline & \multicolumn{2}{|c|}{ Tidak } & \multicolumn{2}{|c|}{$\mathrm{Ya}$} & & & \\
\hline & $f$ & $\%$ & $\mathrm{f}$ & $\%$ & $f$ & $\%$ & \\
\hline \multicolumn{8}{|l|}{ Tipe Tubuh } \\
\hline Gemuk & 32 & 94,1 & 2 & 5,9 & 34 & 100 & 0,000 \\
\hline Kurus & 2 & 11,8 & 15 & 88,2 & 17 & 100 & \\
\hline Total & 34 & 66,7 & 17 & 33,3 & 51 & 100 & \\
\hline \multicolumn{8}{|l|}{ Olahraga } \\
\hline Baik & 24 & 96,0 & 1 & 4,0 & 25 & 100 & 0,000 \\
\hline Kurang & 10 & 38,5 & 16 & 61,5 & 26 & 100 & \\
\hline Total & 34 & 66,7 & 17 & 33,3 & 51 & 100 & \\
\hline \multicolumn{8}{|l|}{ Diet } \\
\hline Baik & 22 & 95,7 & 1 & 4,3 & 23 & 100 & 0,000 \\
\hline Kurang & 12 & 42,9 & 16 & 57,1 & 28 & 100 & \\
\hline Total & 34 & 66,7 & 17 & 33,3 & 51 & 100 & \\
\hline
\end{tabular}

Berdasarkan Proporsi kejadian osteoporosis lebih besar persentasenya pada responden yang kurang melakukan olahraga $(61,5 \%)$ dibandingkan responden yang melakukan olahraga $(4,0 \%)$. Hasil uji statistik didapatkan nilai $\mathrm{P}$ value sebesar $0,000<$ nilai alpha $(0,05)$, ada hubungan yang signifikan antara olahraga wanita menopause dengan kejadian osteoporosis.

Berdasarkan hasil penelitian ada hubungan yang signifikan antara olahraga wanita menopause dengan kejadian osteoporosis di Kelurahan Langgini Wilayah Kerja Puskesmas Bangkinang Kabupaten Kampar. Menurut Wirakusumah (2007), latihan fisik atau olahraga merupakan salah satu upaya terapi pengobatan osteoporosis
Kegiatan ini sangat berguna unt mengurangi rasa sakit dan memperbaiki mobilitas.

Wanita menopause yang secara fisik aktif biasanya mempunyai massa tulang yang lebih tinggi ketimbang orang yang yang pasif dan tidak aktif. Aktivitas fisik yang meningkat memperbesar massa tulang maksimum yang dicapai dan dapat mengurangi jumlah keropos tulang. Wanita menopause yang berolahraga secara teratur diketahui kepadatan tulangnya lebih baik dari pada wanita menopause yang tidak beraktivitas fisik. Hasil penelitian ini menunjukkan bahwa aktivitas (olahraga) wanita menopause mempunyai pengaruh terhadap kejadian osteoporosis terlihat persentase banyak wanita menopause yang 
melakukan aktivitas (olahraga) lebih tidak berisiko terjadinya osteoporosis dibandingkan yang tidak melakukan aktivitas (olahraga), sehingga dapat diartikan semakin sering wanita menopause melakukan aktivitas (olahraga) akan semakin terhindar dari resiko terjadinya osteoporosis.

Proporsi responden yang mengalami osteoporosis lebih besar presentasenya pada responden yang dietnya kurang $(57,1 \%)$ dibandingkan responden yang dietnya baik (4,3\%). Hasil uji statistik chi-square didapatkan nilai $\mathrm{P}$ value sebesar $0,000<$ nilai alpha $(0,05)$, ada hubungan yang signifikan antara diet wanita menopause dengan kejadian osteoporosis di Kelurahan Langgini Wilayah Kerja Puskesmas Bangkinang Kabupaten Kampar.

Berdasarkan hasil penelitian ada hubungan yang signifikan antara diet wanita menopause dengan kejadian osteoporosis di Kelurahan Langgini Wilayah Kerja Puskesmas Bangkinang Kabupaten Kampar.

Menurut Wirakusumah (2009), Pola makan sehari-hari merupakan salah satu upaya yang sangat tepat untuk pencegahan dan pengobatan osteoporosis. Dengan pengaturan pola makan seimbang, zat-zat gizi penting yang dibutuhkan tubuh untuk melakukan seluruh aktivitas dapat terpenuhi.. Konsumsi makanan yang mendukung pencegahan osteoporosis berhubungan dengan konsumsi kalsium, fosfor, vitamin D dan sebagainya. Kekurangan vitamin D, yang biasanya terkait dengan kekurangan kalsium, dapat membuat tulang menjadi lunak (osteomalacia) dan mengakibatkan penurunan massa tulang dan risiko patah tulang lebih besar. Suatu penelitian mengungkapkan bahwa menabung kalsium pada waktu muda akan memperkuat tulang dan mengurangi faktor risiko patah tulang pada saat terjadi penuaan (Wirakusumah, 2007).

Wanita menopause yang melakukan diet yang salah akan berisiko mengalami osteoporosis dibandingkan dengan wanita menopause yang melakukan diet yang benar, yaitu wanita menopause yang cukup mengkonsumsi sumber makanan yang dapat mencegah terjadinya osteoporosis.

\section{KESIMPULAN DAN SARAN}

Berdasarkan analisis data, dapat disimpulkan bahwa :

Kurang dari separoh wanita menopause di Kelurahan Langgini mengalami osteoporosis. Tipe tubuh aktivitas (olah raga) dan diet.Terdapat hubungan yang bermakna antara tipe tubuh wanita menopause dengan kejadian osteoporosis di Kelurahan Langgini. Terdapat hubungan yang bermakna antara aktivitas (olahraga) wanita menopause dengan kejadian osteoporosis di Kelurahan Langgini. Wanita menopause berhubunga dengan kejadian osteoporosis di kelurahan langgini.

Harapan peneliti terhadap Pimpinan Puskesmas Bangkinang, membuat suatu kebijakan untuk melakukan penyuluhan kepada wanita menopause sebagai program rutin. Bagi perawat dan Bidan agar dapat memberikan penyuluhan pentingnya melakukan aktivitas (olahraga) dan peningkatan diet bagi wanita menopause serta melibatkan kader dalam pembentukan posyandu lansia di Kelurahan Langgini. Bagi peneliti selanjutnya dapat meneliti faktor-faktor lain yang berhubungan dengan kejadian osteoporosis pada wanita menopause yang belum diteliti meliputi ras, riwayat keluarga, merokok dan minuman beralkohol.

\section{DAFTAR PUSTAKA}

Clupster. (2009). Bahaya Osteoporosis. http://clupst3r.wordpressDiakses tanggal 02 Januari 2011

Cosman, Felicia. (2009). Osteoporosis: Panduan Lengkap agar Tulang Anda Tetap Sehat. Yogyakarta: BFirst

Doantara. (2008). Aktivitas dan Prestasi Belajar. http://ipotes.wordpress. Diakses pada tanggal 02 Februari 2011 
Fox-Spencer, Rebecca.(2007). Simple Guide Osteoporosis. Jakarta: Erlangga

Gomez, Joan. (2006). Awas Pengeroposan Tulang. Jakarta: Arcan

Hutapea, Ronald. (2005). Sehat dan Ceria di Usia Senja. Jakarta: Rineka Cipta

Javier, MR. (2010). Kupas Tuntas Osteoporosis. Yogyakarta: MultiPress

Junaidi, Iskandar. (2007). Osteoporosis. Jakarta: Bhuana Ilmu Populer

Luluvikar. 2009. Pengetahuan Ibu Tentang Masa Premenpause Di RT $003 \mathrm{RW}$ O2 Kelurahan Benteng Kota Ambon.

http://luluvikar.wordpress.com/2009/08/26/ pengetahuan-ibu-tentang-masapremenopause/. Diakses tanggal 02 Januari 2011

Manuaba, dkk. (2006). Buku Ajar Ginekologi untuk Mahasiswa Kebidanan. Jakarta: EGC
Medicastore. (2008). Osteoporosis Bukan Lagi Ancaman. http://medicastore.com.htm.

Diakses tanggal 29 Desember 2010

Notoatmodjo, Soekidjo. (2005). Metodologi Penelitian Kesehatan. Jakarta: Rineka Cipta

Nursalam. (2008). Konsep dan Penerapan Metodologi Penelitian Ilmu Keperawatan. Jakarta: Salemba Medika

Proverawati, Atikah. (2010). Menopause dan Sindrom Premenopause. Yogyakarta: Nuha Medika

Purwoastuti. (2008). Menopause, Siapa Takut?. Yogyakarta: Kanisius

Wirakusumah, Emma S. (2007). Mencegah Osteoporosis Lengkap dengan 39 Jus dan 38 Resep Masakan. Jakarta: Penebar Plus 